\title{
Measuring creative thinking via holistic standardized assessment: from operationalization to impact on equity
}

Running title: Creative thinking assessment and equity

Michelle Gough*, J.D., Ph.D., and Ashley B. Williams*, Ph.D.

*Project Lead The Way, Indianapolis, IN, USA

\begin{abstract}
Scholars have long debated whether the domains of creativity or creative thinking could be measured on a standardized, computer-graded assessment. A strong body of research has argued that the bias of standardized testing against historically marginalized groups would be mitigated if creativity were added. Adding creativity to standardized assessments also addresses concerns that standardized tests have led to a narrowing of the curriculum. This work was initiated to develop an exemplary approach for measuring creative thinking alongside other skills via standardized assessment and to inspect whether data from over 300,000 assessments provide improved score equity for historically marginalized students. This research paper describes an approach through which evidence of creative thinking may be elicited in a standardized way, provides a model that functionally captures four types of evidence that can provide evidence of creativity, and describes the intrinsic, instructional, and functional benefits of identifying objective, valid evidence of these skills.
\end{abstract}




\section{Future demands on students and the shared needs of institutions of higher education and careers require a new approach for measuring creative thinking}

Project Lead The Way (PLTW) is a leading provider of real-world, activity- project- and problembased (APB) STEM education curricula. The research described was undertaken with grant support from Ascension Health and in furtherance of PLTW's commitment to inspire and engage students to prepare them for the evolving world. A key differentiator for PLTW is its recognition and development of critical and creative thinking, communication, collaboration, problem solving, and ethical reasoning, which PLTW refers to as "Transportable Skills", in addition to subject matter knowledge in the Pathways of Biomedical Science, Computer Science, and Engineering. These transportable skills are especially important to examine as they have been shown in a study by Burning Glass Technologies (2019) to be universally valued across fields and industries.

Consistent with PLTW's thought leadership in curriculum design and pedagogical approach, PLTW redesigned its assessment program to provide both an Informative Assessment Tool, which functions to provide interim feedback to students, and End of Course (EOC) Assessments for PLTW High School Courses to measure and report skill acquisition based on the breadth of skills developed via the PLTW APB instructional approach and the PLTW Curricula that are most critical to students' future success in higher education and/or careers.

Via the APB approach and the PLTW curricula, students apply and develop skills that include both subject matter technical knowledge and the Transportable Skills. The nature of the methodology results in integrated development and application; thus, to be authentic to the classroom experience, the redesigned Assessments needed to not only measure the most critical knowledge and skills, but demanded inclusion of both unidimensional, i.e., isolated to one knowledge domain, and integrated tasks that simultaneously cover multiple knowledge domains. 
In addition to the necessity of curricular alignment, the PLTW EOC assessments were reengineered with two core aims that drove their design: 1) authenticity to the APB, inquiry-driven approach of PLTW programs, and 2) real-world applicability. In the "real" world, individuals must apply complex and combined skills rather than a single skill in a vacuum. Said differently, the career world requires professionals who can do more than solve a formula or recite an engineering or scientific concept - these abilities must be applied in the context of a problem, product, or challenge. The successful navigation of these professional situations often requires collaboration with others and group communication. Furthermore, one may be asked to approach problems and challenges from a different angle because the first approach was not palatable or accepted whether due to cost, supply chain issues, or other preferences or considerations. It is in these contexts that PLTW EOCs measure both subject matter and Transportable Skills. To this end, it was necessary to develop thought-leading approaches regarding evidence-centered design (Gough, n.d.), multidimensionality, and standardized holistic assessment.

Therefore, the challenge posed to these authors, on behalf of PLTW and in their capacities as Chief Assessment Officer and Vice President of Research for PLTW, was not to assess the overall creativity potential or capacity of a student, but rather to design a valid way to measure their ability to apply creative thinking in the context of the STEM subjects taught in the PLTW Pathways of Computer Science, Biomedical Science, and Engineering. Furthermore, this measurement approach had to be consistent with the learning approaches and behaviors encouraged via the PLTW APB instructional approach. Finally, the use of traditional creativity assessments (e.g., The Torrance Tests of Creativity, TCCT) were not appropriate to achieve this objective because the measurement of creative thinking as a latent trait in the context of PLTW assessments must be applied in the context of the pathways. Notably, Kaufman (2010) pointed out that "if it were easy to add a construct like creativity to a standardized test, it would be done." To successfully incorporate creative thinking into a computer-delivered standardized test, a new approach for 
assessing creative thinking as an applied skill was required. Furthermore, this approach was designed to avoid limiting curricular content, which has been an issue in discussions of standardized test value (Labaree, 2011).

\section{Defining creative thinking with a focus on observable evidence}

Multiple leading creativity scholars have recently articulated the need for renewed conversation about how creativity is studied and measured (Glăveanu et al., 2019), and herein, the authors of this article describe the approach that they developed for PLTW to assess creative thinking, which answers this charge.

As acknowledged above, numerous approaches have been developed and applied to assess creativity since the blossoming of creativity research in the 1950s (Barbot et al., 2011). The fulfillment of PLTW's aim to develop holistic assessments that measure the five transportable skills (i.e., critical and creative thinking, communication, collaboration, problem solving, and ethical reasoning) simultaneously with the measurement of subject matter knowledge in a single assessment instrument required a paradigm shift in what it means to assess creative thinking. To this end, a Creative and Critical Thinking (CCT) Technical Advisory Panel was established to support the development of a novel framework for assessing creative thinking. This first-of-itskind panel (Note 1) brings together academic and industry experts as well as PLTW teachers with the expectation that their collaboration would lead to an intellectual synergy that would provide both the innovation as well as the validity foundation necessary to support PLTW in reaching its goals in this area.

The definition of creativity remains nebulous and is highly debated. For example, Treffinger (1996) collected and discussed over 100 different definitions from the extant literature as of 1996, and more recently Corazza (2016) has proposed a divergent definition (a so-called dynamic 
definition), i.e., that “creativity requires potential originality and effectiveness". These authors' development of a unified approach to measure creative thinking in the context of standardized testing did not occur in a vacuum. For the development of the 2021 version of the Programme for International Assessment (PISA) test, the Organisation for Economic Cooperation and Development (OECD) adopted a definition of creative thinking formulated by Rosen and Tager, i.e., "[Creative thinking is] the capacity to effectively engage in a process of generating, implementing, and evaluating novel and contextually useful ideas, solutions, or insights” (Rosen \& Tager, 2014, p. 252).

This definition includes a broadly accepted and key concept of creative thinking, i.e., the generation of novel thoughts. However, it is limited and is insufficient to support these authors' specific goal of collecting evidence of creative thinking in the PLTW tests, namely, to link the assessment of creative thinking to skills demanded by employers across fields and higher education institutions. The authors required a more nuanced and comprehensive definition of creative thinking, which was developed by CCT Advisory Panel:

Creative thinking is the intellectual process of generating valuable new insight, ideas, and solutions or synthesis of existing concepts. In the context of STEM education, effective creative thinking occurs within bounds typically imposed by the laws that govern the domain under study, and also under constraints deemed to be acceptable practice by professionals in the field. Creative thinking in this context generates solutions that are novel, useful, and in conformance with applicable constraints (Gough \& Patz, 2019a).

Importantly, this definition relates creative thinking to the demands of professionals in the STEM fields - a central and overarching principal that guides PLTW's curriculum and assessment design processes. 
Creativity is an inherently fuzzy concept and as such, it has been suggested that its measurement is intrinsically complicated and that its quantification is impossible (Thompson et al., 2010). These authors reject these opinions and believe that the construction of an operational definition of creative thinking based on the theoretical definition developed by the CCT Advisory Panel

(Gough \& Patz, 2019a) can support the measurement of students' potential for creative thinking. Indeed, several leading scholars in the creativity field have recently affirmed the validity and need of applying such an approach to measure creative thinking:

Creativity research is intrinsically complex, especially when it comes to using tests and other similar instruments. In reporting research, we should use the notion of creativity critically and reflectively. The propositions outlined here describe creativity as a complex phenomenon for which many facets may be identified and studied. If a study measures a facet of creativity (such as divergent thinking or creative selfbeliefs), it should be labeled as such - and not equated with "creativity per se," even if this concept is mentioned as a larger referent. We must acknowledge that we always define and measure creativity from within a certain paradigm and discipline (Glăveanu et al., 2019).

It is well accepted that ambiguous or nebulous concepts can be quantified via rational and consistent methods (see Williams, 1999 for further discussion of this topic). Furthermore, a common and accepted approach in test design is the use of objectively observable traits to allow the inference of the test subjects ability in a theoretical construct (Wilson, 2005). An approach for operationalizing creativity has been discussed in a high-profile publication (Glăveanu, 2014) that has since been responded to extensively (Hui, 2015; Hennessey, 2015; Runco, 2015; Moran, 2015; Tang, 2015; Tanggaard, 2015; Lubert \& Caroff, 2015). These authors operationalized creative thinking (distinct from creativity) into four factors that can be directly measured via the use of the 
innovative and holistic PLTW testing approach: proliferation, fluidity, bending and elaboration (discussed in detail below). While it is likely true that, as Thompson (2010) argued, the measurement of creative thinking as a whole is impossible, these authors argue that the evaluation of these individual factors, henceforth referred to as creative thinking operational domains (CTODs), via innovative task models can elicit evidence of a student's capacity to apply creative thinking in the context of subject-specific scenarios. Thus, direct measurement of these observable traits functions as a proxy for measuring the latent trait of creative thinking.

Based on a systematic analysis of the past and current literature on approaches to defining and assessing creativity, and within the framework of the theoretical definition developed by the CCT Advisory Panel, these authors formulated the following operational definition of creative thinking for application:

A student's creative thinking skills may be observed, and therefore measured, via task models that elicit evidence of the student's ability to apply any of, or a combination of, the four CTODs (i.e., proliferation, fluidity, bending, and elaboration).

This definition supports the construction of a syllogistic model to that the authors were able to apply during assessment develop and design to ensure that assessment items do indeed elicit evidence to support the claims made regarding creative thinking:

1. Evidence of creative thinking may reasonably be summarized as falling within the following CTODs: proliferation, fluidity, bending, or elaboration.

2. Items that measure creative thinking elicit evidence of proliferation, fluidity, bending, or elaboration.

3. Items that do not elicit evidence of the above do not elicit evidence of creative thinking.

4. Therefore, only items satisfying condition (2) may be mapped to creative thinking, and others must be rejected until modified (Note 2). 


\section{Justification for the CTODs of proliferation, fluidity, bending, and elaboration}

Based on earlier work from Guilford (1950a, 1950b, 1966, 1968), Torrance considered four semiquantifiable factors for scoring divergent thinking and problem-solving skills, which he applied in the development of the Torrance Tests of Creative Thinking (TTCT) (Torrance, 1962, 1965, 1966a, 1974, 1975). Kim has provided a detailed review of the TTCT from a contemporary perspective (Kim, 2006). These original factors are:

1. Fluency - The total number of interpretable, meaningful and relevant ideas generated in response to a given stimulus.

2. Flexibility - The number of different categories of relevant responses.

3. Originality - The statistical rarity of the responses.

4. Elaboration - The amount of detail in the responses.

It has been argued that the figural version of the TTCT (TTCT-F), which is a non-verbal test built around figure-based task models, is the most commonly used creativity test (Plucker \& Renzulli,

1999). Furthermore, the TTCT-F validity as an assessment of creativity has been affirmed (Kim, 2017). Torrance's original concepts provided a scaffold on which these authors developed the novel CTODs. The CCT Advisory Panel both directly and indirectly expressed a need for further refinement (Gough, 2019, July 14). Thus, the several closely related, but adapted CTODs were defined (summarized in Table 1).

\section{Proliferation}

Torrance's original concept of fluency reflects the number of ideas generated by the student, and importantly, it requires that the ideas be directly linked to the given stimulus, i.e., that the responses were generated via an intentional thought process directed at the provided stimulus. In the modern workplace, employees must often apply creative thinking to solve problems, and 
towards the goal of assessing creative thinking as a transportable skill, these authors argue that the fluency of idea generation is a key feature of this skill. Similar to Torrance's original concept for measuring fluency, proliferation is measured via task models that provide opportunities for students to generate multiple relevant solutions to a given problem within the context of the relevant subject matter such that a higher capacity for proliferation is indicated by a higher number of acceptable solutions.

\section{Fluidity}

Torrance's concept of flexibility involves examining the number of different categories into which a set of responses can be sorted. These authors propose the CTOD of "fluidity", which centers on the generation of multiple ideas based on different perspectives and multiple approaches and strategies. Stated simply, fluidity is the ability to generate or use of multiple ideas that can be sorted into multiple categories.

\section{Bending}

Bending expands on the concept of assessing fluidity as an operational domain of creative thinking. These authors propose, consistent with advice and support from the CCT Advisory Panel (Gough, 2019), the use of constraints, i.e., the addition of variables that limit the scope of possible solutions to a problem. To distinguish this more specific concept of fluidity (and Torrance's flexibility) this CTOD was named bending (see Note 2). Torrance's original concept of flexibility is maintained in the definition of this CTOD, as bending indeed reflects the ability to approach the same problem from a number of different angles; however, the adoption of this alternative terminology reflects both the suggestions of the CCT Advisory Panel related to the emphasis of constraints and avoids confusion with Torrance's original use of the term flexibility.

\section{Elaboration}


Torrance's original concept of elaboration is related to the level of detail that can be elaborated in relation to an idea. In this CTOD, Torrance's original concept of elaboration is generally maintained, i.e., elaboration refers to the ability of the student to provide details of their ideas generated in response to a stimulus. Thus, this term is maintained.

As discussed below, these authors assert that the design of test items that elicit evidence of the student's ability to apply these CTODs in various problem-based task models will provide opportunities for students to demonstrate their capacity for creative thinking. 
Table 1. Definitions of creative thinking operational domains (CTODs)

\begin{tabular}{|c|c|}
\hline CTOD & Description \\
\hline Proliferation & $\begin{array}{l}\text { The generation of multiple intellectually } \\
\text { intentional solutions to a given problem. }\end{array}$ \\
\hline Fluidity & $\begin{array}{l}\text { The generation of multiple intellectually } \\
\text { intentional solutions to a problem that span } \\
\text { intellectually distinct categories. }\end{array}$ \\
\hline Bending & $\begin{array}{l}\text { The ability to provide an intellectually } \\
\text { intentional shift in approach or solution due to } \\
\text { the presentation of a change in the original } \\
\text { variables presented in a problem, including, } \\
\text { inter alia, a change in the elements present, } \\
\text { errant early hypotheses, a shift in timelines, a } \\
\text { change in available materials, skills available, } \\
\text { available monies or expected costs, or desired } \\
\text { outcome. }\end{array}$ \\
\hline Elaboration & $\begin{array}{l}\text { The generation of details related to a solution to } \\
\text { a problem. }\end{array}$ \\
\hline
\end{tabular}




\section{Application of the CTODs in item design}

The CTODs discussed here are highly amenable for use as guiding principles in the design of items consistent with the syllogistic model provided above. Importantly, the development of creative thinking test items is limited only by the test designer's own creativity. The follow example assessment items are designed to provide insight into the practical implementation of the newly defined CTODs in the assessment of creative thinking. In this example, constraints imposed by task model or scoring are not consider. The following items are linked by a common narrative established via the following stimulus:

You are the biological safety officer for a research building in which a new, extremely contagious virus is being studied. Even though researchers are required to work in "space suits" in sealed laboratories, a clinician, who was not in a lab space, noticed that she was showing symptoms of the virus as she is preparing to leave the building for the evening. To prevent the release of the contagion into the outside world, which could possibly lead to a worldwide pandemic, you and your team must follow damage mitigation protocols to contain the virus within the building. Research with tracer viruses has shown that viral contamination of a single doorknob in a busy building can be spread to up to $60 \%$ of surfaces within several hours.

The purpose of the stimulus is to establish a rich context in which the other items exist. Torrance (1966b) argued that creativity benefits from a warm-up that would result in students' awareness of a problem to be solved, provoke questioning to make students think of information in new ways, or stimulate students' curiosity and desire to know more. Rich stimuli are consistent with this concept, and as such, they may stimulate creative thinking in the test taker. What follows are five example test items that demonstrate how careful design can elicit evidence of the CTODs. 
Item 1. Brainstorm reasonable approaches for mitigating spread of the virus through the building and between personnel.

To brainstorm reasonable solutions to a problem established in the stimulus, the test taker must proliferate multiple intellectually intentional ideas. The similarity between proliferation and the act of brainstorming is clear, and the design of items that involve brainstorming can be useful for eliciting evidence of proliferation.

In this exemplar, the elicitation of evidence of fluidity occurs via a two-step process. First, the test taker is tasked with sorting their ideas from item 1 into a given set of "bins", or classes of responses. This act of sorting highlights to what extent the responses to item 1 cross different categories, a key feature of fluidity, perhaps also demonstrating intrinsic fluidity in these responses. The identification of a deficiency in one or more bins supports more direct measurement of fluidity, as modelled by the next item.

Item 3. Choose the bin with the fewest ideas and then generate additional ideas that can be classified into this bin.

In responding to this item, the test taker is required to confront the category of responses least obvious to them and then to generate additional ideas that fit into that category. Fluidity of thought is indicated by ability to further ideate in this unrepresented space.

As discussed above, bending involves approaching a problem under some defined constraints. Careful introduction of a constraint that requires a "work around" or recasting of a problem can be used to elicit evidence of bending. In the following item, the narrative established by the stimulus is extended to introduce a real-world and plausible constraint.

Item 4. You are your colleagues consult and determine that the use of masks will play a critical role in the mitigation effort. Masks are only stocked for the research personnel; therefore, there 
are not enough masks to also include the administrative and support staff. Because the building is sealed from the outside, this problem must be solved used resources available within the building. Brainstorm solutions for overcoming the mask shortage.

Note that this item is left intentionally open ended. In designing such an item, one might be tempted to phrase the question more specifically, e.g., brainstorm solutions for creating makeshift masks; however, such specificity is counter to the concept of creative thinking. The most critical feature of this item is that the test taker has freedom to generate ideas that are amenable to a constraint, while their ability to ideate multiple solutions (i.e., proliferation) that span multiple categories (i.e., fluidity) is not stymied.

The final CTOD is elaboration. The below example provides only one of many possible approaches to measuring this CTOD. The elicitation of evidence of elaboration requires that the item provides the test taker with an opportunity to provide details of either an idea that they generated previously in the assessment, or details of some process or other solution that is well grounded in subject area knowledge.

Item 5. To mitigate the spread of the virus it is important to remove uninfected personnel from the building. To this end, everyone in the building must be tested as rapidly as possible. Although there are an adequate number of tests, most of the laboratory technicians had already left the building before the incident. Only clinical personnel, who are not experienced in laboratory techniques, remain. You have been tasked with training the clinicians to complete the tests. Elaborate a detailed list of all steps and processes required to implement a testing program using clinical personnel.

In responding to this item, the test taker must invoke their subject-specific knowledge, while also ideating intellectually intentional solutions that might not have been explicitly discussed 
previously. Importantly, this item is left very open ended, as responses could span multiple categories without limitation.

In these examples, each item primarily elicits evidence of one CTOD. However, while each CTOD can be considered to be an independent construct during item design, they are, in fact, highly interconnected, being either additive or even synergistic with each other. In this way, it is not necessary for a student to apply or demonstrate only one CTOD at a time to solve a given problem. As represented by the model in Figure 1 by the overlap of the CTODs, depending on their unique aptitudes and creative thinking skills, students might invoke the use of one or more CTODs to solve real-world problems. Thus, the design of items that offer students opportunities to provide evidence of their use of one or more CTODs simultaneously would be favored. Depending on the perspective of the observer, the provided examples may be interpreted to touch multiple CTODs, thus representing multi-dimensional items. This concept of increasing complexity is illustrated by the progression toward the center of the figure via the levels delineated by the dashed lines. For example, some items might elicit evidence of only proliferation (P), fluidity (F), bending (B), or elaboration (E). More complex items could be classified as PE, PB, PF, FB, BE, or FE when they involve two CTODs; PBE, PFB, FBE, or PFE when they involve three CTODs; or PFBE when they involve all four CTODs. An ideal assessment would include a mixture of these various classes of items to provide achievable tasks for students of all levels. 


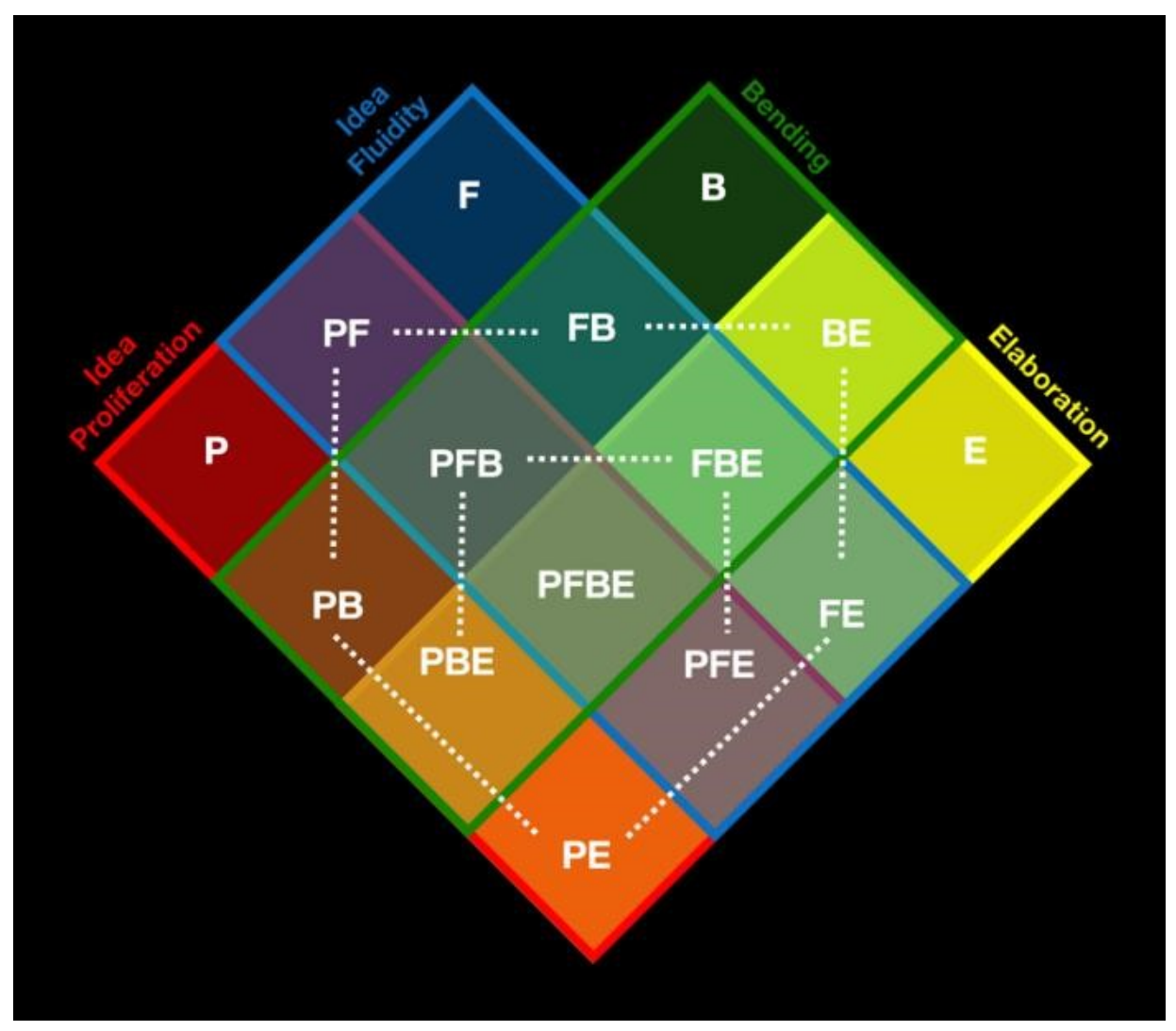

Figure 1. A model of the relationships between the CTODs. Each CTOD is represented by a colored rectangle, and the rectangles are overlapped to show how the CTODs can relate to each other. The dotted white lines highlight the different levels of overlap complexity, from two CTODs to three CTODs, with the intersection of all four domains lying at the center of the model. 


\section{Implications for assessment bias}

A strong body of scholarship has argued that measures of creative thinking could mitigate standardized test bias (for example, see Kaufman, 2006, 2010 and Kim, 2015). For the purposes of this paper, standardized test bias is defined as statistically significant and disproportionate performance by students based on immutable characteristics. As mentioned above, the authors were researching improvements to the measurement of ethical reasoning concurrently with this

research. There were overlaps between and amongst the two endeavors. In terms of bias, the scoring data from the redesigned PLTW EOC Assessments, which included

14 tests across the three different pathways (i.e., Computer Science, Biomedical Science, and Engineering), demonstrated that measurement of Transportable Skills simultaneously with subject-specific knowledge significantly impacted the gender and racial bias that has pervaded standardized testing for decades, including the prior PLTW test series.

Inclusion of Transportable Skills items in the EOC assessments did not fully eliminate the achievement gap observed for marginalized students. Remarkably, however, marginalized students tended to score higher on transportable skills items. Figure 2 illustrates the difference in performance on Transportable Skills items between male and female students. Across 12 EOC assessments for which relevant data were available, female students outperformed male students in these skills, and similar results were observed for other demographics, including Hispanic/Latinx and African American students. In the gender-related data shown, a clear outlier is the Computer Science Essentials (CSE, red dot). This difference could be due to a variety of largely intractable factors, but it could be related to the under representation of females in the testing population (approximately 27\%). This bias-mitigating effect was most notable for ethics and professionalism and communication tasks that require "code switching," i.e., shifting 
language (Auer, 2016) or behavior (Morton, 2013) in consideration of audience, admitting mistakes, and trying to cure them, or exhibiting empathy in particular. These skills, cognitively, require creative thinking and are therefore overlapped for test mapping and in relation to this research (Henriksen et al., 2016; Gough \& Patz, 2019b). 


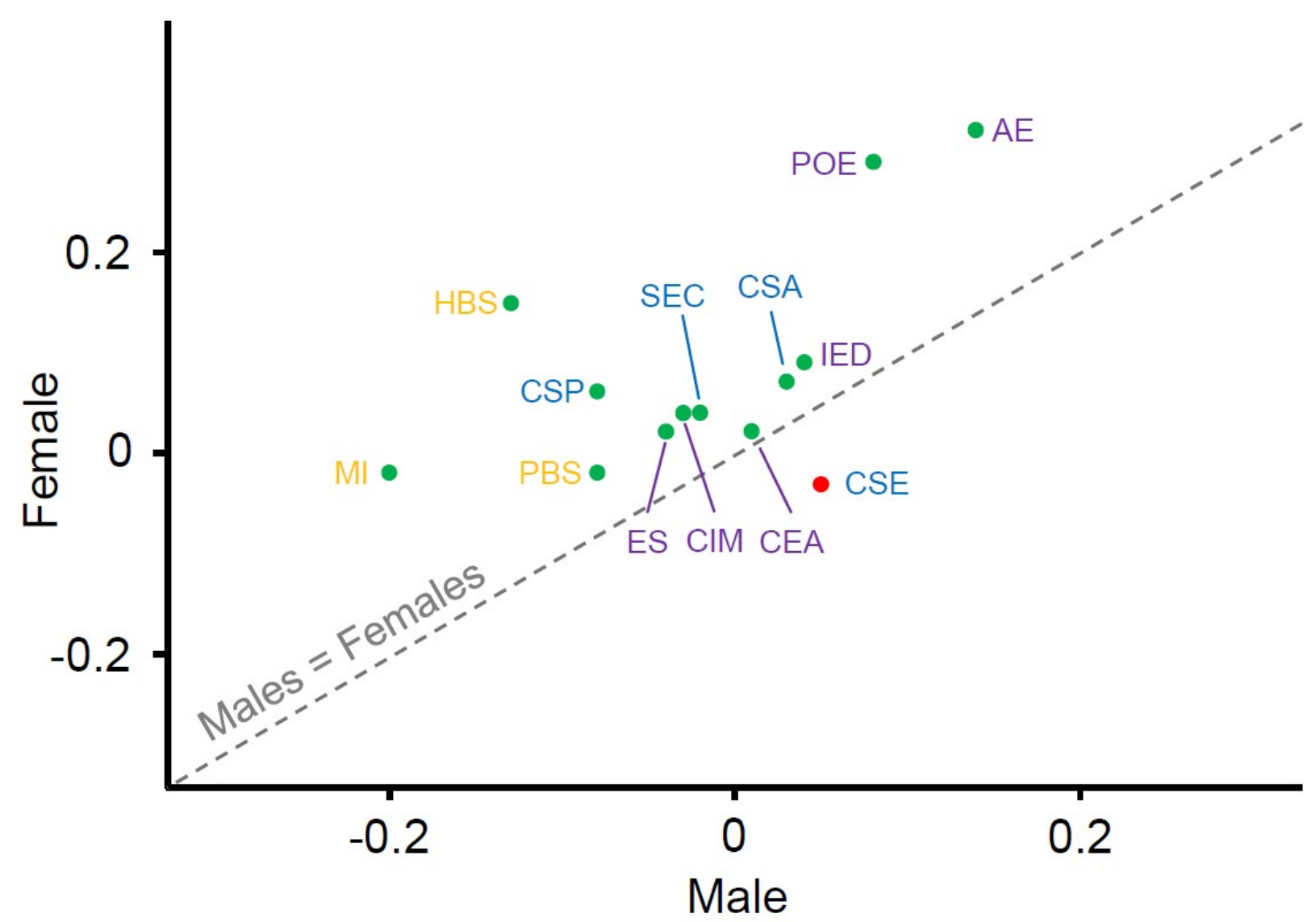

Figure 2. Comparison of female:male performance on Transportable Skills items over thirteen PLTW EOC Assessments (2018/19 version). For each student, the difference between their aggregate score on subject-specific items and their aggregate score on the Transportable Skills items was calculated, referred to as the relative strength (RS). For each test, the mean RS values were calculated for male and students individually, and these values from each test are plotted in the figure. Points that lie above the dotted line indicate that female students performed better, while points that lie below the line indicate stronger performance by male students. Additional information is provided in the text. 
Quite remarkably, following the introduction of Transportable Skills items into the EOC assessments in the 2018/2019 version, the difference in the overall test scores between male and female students decreased in 8 out of the 12 tests for which data from both years were available (Figure 3). While the above score results data show that students from marginalized populations can excel at Transportable Skills items on a standardized assessment, these results show that the magnitude of the effect is sufficient to affect the overall outcome of the assessment; therefore, we conclude that the inclusion of Transportable Skills items on standardized testing could be a powerful tool for mitigating standardized testing along gender and other demographic lines.

These data are significant for the field of assessment specifically and for education in general., and the approach was applied to 14 separate assessments in the 2018/19 school year (4 Computer Science, 5 Biomedical, 7 Engineering). The items or tasks were written by over 400 different experts, with backgrounds specific to each pathway, including over 200 PLTW teachers, who have always been closely involved in item design. Over 335,00o assessments were administered to over 335,000 distinctive students across all 50 states. The curriculum upon which the students were taught did not change, and the professional development and PLTW-specific APB instructional model used when teaching the 14 courses remained consistent. The only change was what Transportable Skills domains were included on the test blueprint. These data therefore suggest that marked disproportional aggregate score data on assessments, i.e., test bias, is a choice made by test designers - What content is tested impacts the scores along gender and racial lines.

This deeper insight into student performance leads to fairer and more balanced assessments that can support marginalized students in reaching their full potential by increasing self-efficacy by scores that affirm strengths, and through the careful design, emphasize the relevance and criticality of the fully panoply of skills measured on the assessments. 

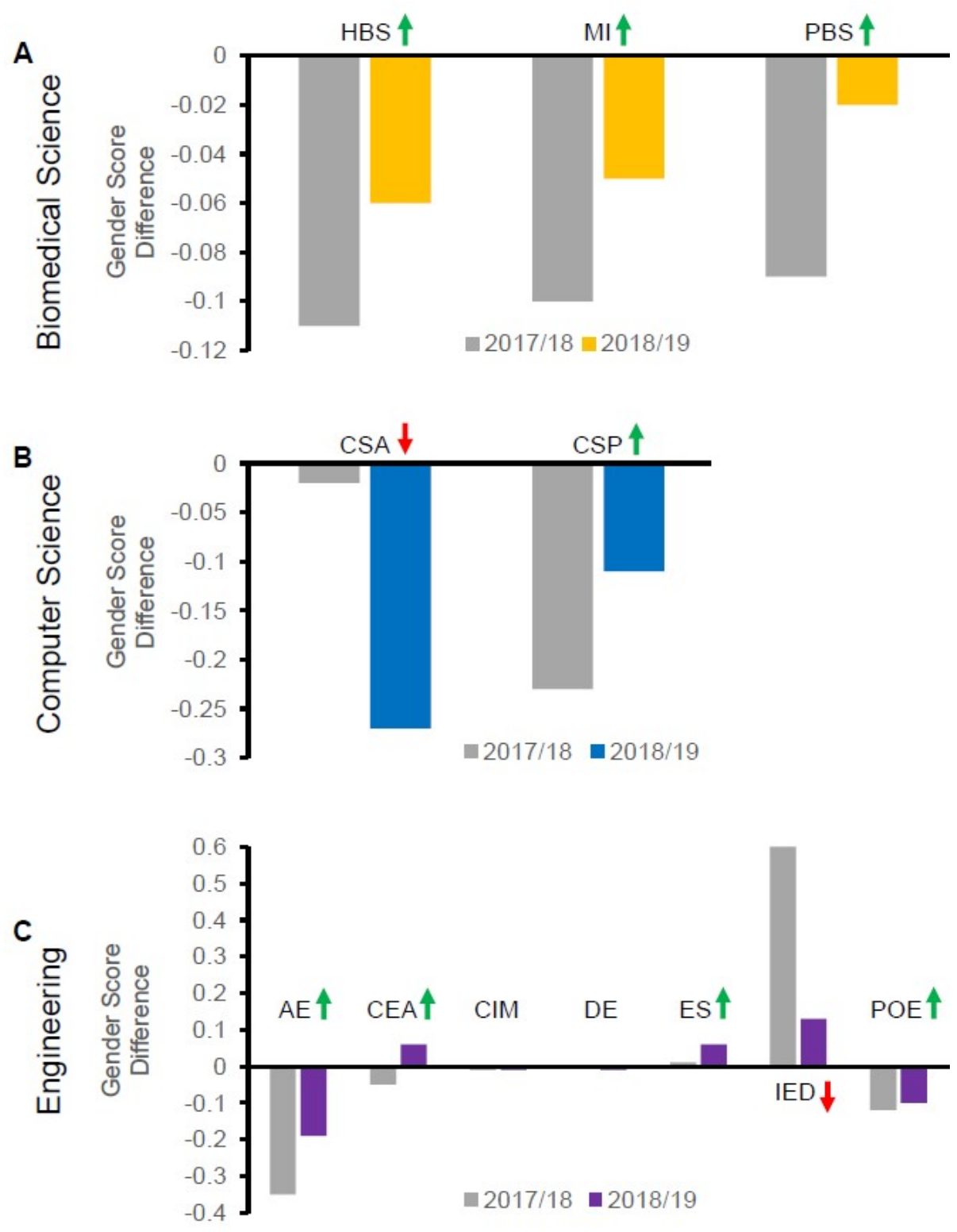

Figure 3. Shown are the differences in overall test score for the 2017/18 and 2018/19 PLTW

EOC Assessments for the Pathways of Biomedical Science (A), Computer Science (B), and Engineering (C). The bars represent the difference between the overall scores for male students and those for female student such that a negative value indicates an achievement gap in favor of males. Green arrows indicate a mitigation of the achievement gap in favor of females and red arrows indicate an increase in the achievement gap in favor of males following the addition of 
(Figure 3 legend, continued) Transportable Skills items in the 2018/19 tests. The absence of an arrow indicates no difference. The results are reported as the effect size to allow comparison across years and tests. See the text for further discussion.

\section{Outlook: Innovative assessment of creative thinking}

In a study by Burning Glass Technologies (2019), creative thinking was identified as among the top in-demand skills valued by employers across industries and career areas. Therefore, objective measurement of skills in creative thinking (and other Transportable Skills) is intrinsically valuable for the test taker, instructionally valuable for teachers and parents/guardians, and it is valuable for college admissions and employers who seek to recruit teams and classes of students with diversity of thought. The operationalization of creative thinking (as a distinct construct from creativity) presented here provides an approach that can be used to elicit evidence of creative thinking in the context of assessments. While the example items discussed here are firmly rooted in the realm of biomedical science, the principles described, in the form of the four CTODs, can be applied in any field in which multiple or different creative solutions to problems can be ideated. The authors propose that meaningful and objective measurement of creative thinking, which can practically be implemented even on computer-delivered assessments given the development of appropriate task models, will add a powerful new dimension to assessment.

\section{Declaration of conflicts of Interest}

The author(s) declared no potential conflicts of interest with respect to the authorship and/or publication of this article.

\section{Funding}

This research was made possible by grant funding from Ascension Health as well as volunteered expert participation advice from experts from Dow Chemical Company. 


\section{Notes}

1. Gough previously established a the PLTW Ethics Advisory Committee in 2018 with the same needs and aims. The two advisories are the first of their kind in the field of measurement. This work was also made possible, in part, from grant funding from Ascension Health. The authors highlight that the work in advancing measuring ethical reasoning and work in advancing critical and creating thinking together led to more insights and findings than done unitarily.

2. The term "bending" was chosen as a tribute to Anthony Brandt, who was instrumental in the writing of this article. In the book The Runaway Species (Eagleman \& Brandt, 2017), Brandt and Eagleman discuss the development of the artificial heart and the constraints on the required mechanical properties imposed by human anatomy. Consistent with the CTOD of bending discussed here, doctors were required to work around these constraints to develop a novel solution that allowed the artificial heart to function within the chest cavity. 


\section{References}

Auer, P. (2016). Code-switching in conversation: language, interaction and identity. London:

Routledge Taylor and Francis Group.

Barbot, B. (2011). Assessing Creativity in the Classroom. The Open Education Journal, 4(1), 5866. doi: 10.2174/1874920801104010058

Burning Glass Technologies (2019). The Power of Transportable Skills. https://www.burningglass.com/wpcontent/uploads/ThePowerOfTransportableSkills.pdf

Corazza, G. E. (2016). Potential Originality and Effectiveness: The Dynamic Definition of Creativity. Creativity Research Journal, 28(3), 258-267. doi: 10.1080/10400419.2016.1195627

Eagleman, D., \& Brandt, A. (2017). Runaway Species: how human creativity remakes the world. New York, NY: Catapult.

Glăveanu, V. P., Hanson, M. H., Baer, J., Barbot, B., Clapp, E. P., Corazza, G. E., ... Sternberg, R. J. (2019). Advancing Creativity Theory and Research: A Socio-cultural Manifesto. The Journal of Creative Behavior. doi: 10.1002/jocb.395

Glăveanu, V. P. (2014). The Psychology of Creativity: A Critical Reading. Creativity: Theories - 
Research - Applications, 1(1), 10-32. doi: 10.15290/ctra.2014.01.01.02

Gough, M. (n.d.), Daubert-style Evidence Centered Design, forthcoming.

Gough, M., Patz, R., Dykeman, K., Enneking, T., Gaines, J., Harris, A., Henriksen, D., Hobb S., Johnson, K., Kerr., B., Kim, K. H., Koocher, G., Misko, T., Omura, G., Somma, M., Watts, B., White, A. (2019a, July 11). Measuring Critical and Creative Thinking: Process and Results of a PLTW Construct Definition Workshop. Unpublished.

Gough, M., \& Patz, R. (2019b, January 7). Measuring Ethics and Professionalism in Projectbased STEM Education: Process and Results of a PLTW Construct Definition Workshop. Unpublished.

Guilford, J. P. (1950). Creativity. American Psychologist, 5(9), 444-454. doi: 10.1037/hoo63487

Guilford, J. P. (1966). The Structure of Intellect. Readings in Clinical Psychology, 53-81. doi: 10.1016/b978-1-4832-0087-3.500o8-5

Guilford, J. P. (1971). The nature of human intelligence. New York: McGraw-Hill.

Hennessey, B. A. (2015). Comment on “The Psychology of Creativity: A Critical Reading” by Vlad Petre Glăveanu. Creativity. Theories - Research - Applications, 2(1), 32-37. doi: 10.1515/ctra-2015-0004 
Henriksen, D., Mishra, P., \& Fisser, P. (2016). Infusing Creativity and Technology in 21 st Century Education: A Systemic View for Change. Educational Technology \& Society, 19 (3), 27-37.

Hui, A. N. N. (2015). Commentary on The Psychology of Creativity: A Critical Reading. Creativity. Theories - Research - Applications, 2(1), 56-63. doi: 10.1515/ctra2015-0008

Kaufman, J. C. (2006). Self-reported differences in creativity by ethnicity and gender. Applied Cognitive Psychology, 20(8), 1065-1082. doi: 10.1002/acp.1255

Kaufman, J. C. (2010). Using Creativity to Reduce Ethnic Bias in College Admissions. Review of General Psychology, 14(3), 189-203. doi: 10.1037/a0020133

Kim, K. H. (2006). Can We Trust Creativity Tests? A Review of the Torrance Tests of Creative Thinking (TTCT). Creativity Research Journal, 18(1), 3-14. doi: 10.1207/s15326934crj1801_2

Kim, K. H. (2015). Cultural bias in assessment: can creativity assessment help? International Journal of Critical Pedagogy, 6(2), 129-148.

Kim, K. H. (2017). The Torrance Tests of Creative Thinking - Figural or Verbal: Which One Should We Use? Creativity. Theories - Research - Applications, 4(2), 302-321. doi: 
10.1515/ctra-2017-0015

Labaree, D. F. (2011). Targeting Teachers. Dissent, 58(3), 9-14. doi: 10.1353/dss.2011.0068

Lubart, T., \& Caroff, X. (2015). Has Creativity Research Become a Trivial Pursuit? Creativity.

Theories - Research - Applications, 2(1), 44-48. doi: 10.1515/ctra-2015-00o6

Moran, S. (2015). Creativity is a Label for the Aggregated, Time - Dependent, Subjective

Judgments by Creators and by Adopters. Creativity. Theories - Research -

Applications, 2(1), 64-69. doi: 10.1515/ctra-2015-0009

Morton, J. M. (2013). Cultural Code-Switching: Straddling the Achievement Gap. Journal of

Political Philosophy, 22(3), 259-281. doi: 10.1111/jopp.12019

Plucker, J. A., \& Renzulli, J. S. (1998). Psychometric Approaches to the Study of Human

Creativity. Handbook of Creativity, 35-61. doi: 10.1017/cbo9780511807916.005

Rosen, Y., \& Tager, M. (2014). Making Student Thinking Visible through a Concept Map in

Computer-Based Assessment of Critical Thinking. Journal of Educational Computing

Research, 5o(2), 249-270. doi: 10.2190/ec.50.2.f

Runco, M. A. (2015). A Commentary on the Social Perspective on Creativity. Creativity.

Theories - Research - Applications, 2(1), 21-31. doi: 10.1515/ctra-2015-0003

Tang, M. (2015). Revisiting the Systems Approach: Commentary on Glăveanu's Paper “The 
Psychology of Creativity: A Critical Reading." Creativity. Theories - Research -

Applications, 2(1), 79-84. doi: 10.1515/ctra-2015-0012

Tanggaard, L. (2015). Reaching Out For Everyday Life Creativity. Creativity. Theories -

Research - Applications, 2(1), 75-78. doi: 10.1515/ctra-2015-0011

Thompson, T., Lamont-Robinson, C., \& Younie, L. (2010). 'Compulsory creativity': rationales, recipes, and results in the placement of mandatory creative endeavour in a medical undergraduate curriculum. Medical Education Online, 15(1), 5394. doi:

10.3402/meo.v15io.5394

Torrance, E. P. (1974). Torrance tests of creative thinking: norms-technical manual.

Bensenville, IL: Scholastic Testing Service.

Torrance, E. P. (1962). Guiding creative talent. Englewood Cliffs, NJ: Prentice-Hall.

Torrance, E. (1965). Scientific Views of Creativity and Factors Affecting Its Growth. Daedalus, 94(3), 663-681. Retrieved April 21, 2020, from www.jstor.org/stable/20026936

Torrance, E. P. (1966a). Torrance tests of creative thinking. Princeton, NJ: Personnel Press, Inc.

Torrance, E. P. (1966b). The Torrance Tests of Creative Thinking-Norms-Technical Manual Research Edition-Verbal Tests, Forms A and B-Figural Tests, Forms A and B.

Princeton, NJ: Personnel Press. 
Torrance, E. P. (1975). Issues \& advances in educational psychology: a book of readings.

Itasca: Peacock.

Treffinger, D. J. (1998). Creativity, Creative Thinking, and Critical Thinking: In Search of Definitions. Gifted and Talented International, 13(1), 46-46. doi:

10.1080/15332276.01.11672879

Williams, R. (1999). Operational Definitions and Assessment of Higher-Order Cognitive Constructs. Educational Psychology Review, 11(4), 411-427. Retrieved April 21, 2020, from www.jstor.org/stable/23361508

Wilson, M. (2012). Constructing Measures An Item Response Modeling Approach. Hoboken:

Lawrence Erlbaum Associates. 